\title{
Getting ready for online learning
}

In order to flatten the rate of COVID-19 infections in South Africa, Rhodes University will be moving to online learning from 20 April 2020. Online learning means that you will not return to Makhanda but will receive all your learning materials online - via your phone or computer - where you currently live.

Online learning can be a fun and creative way to learn, but it can also be daunting, and many students may experience barriers. For example, you might find that receiving information on a webpage is overwhelming, you might be worried you won't be able to make sense of it, and you might experience difficulties connecting to the internet.

This short guide provides some useful tips and recommendations for how to shift to online learning more easily.

\section{Don't panic}

We understand that you are living in a very confusing and stressful time. We also recognize that not all of us know how to use technology well, and that not all of us have internet access at home or money to buy extra data. We are here to help you succeed!

\section{Moving to online learning}

Instead of returning to campus, you will now receive your lectures, course outlines and useful documents online on the RUConnected learning platform. This means that you can continue your studies at home.

To find out how to access your course online, you can watch the introductory video which

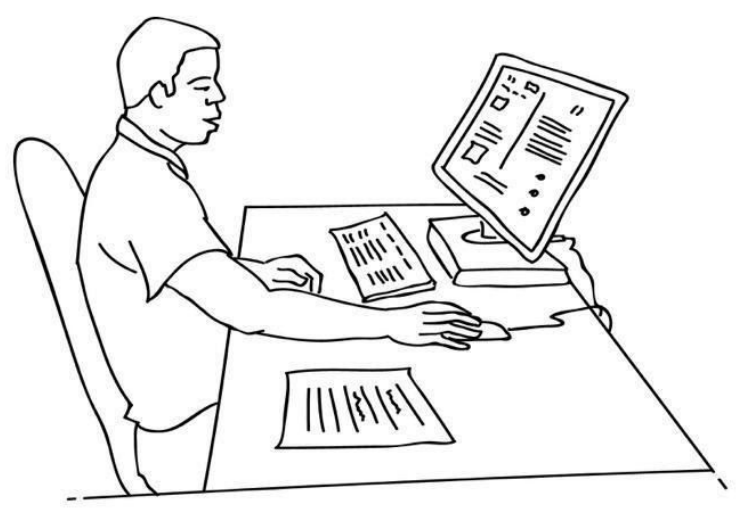
demonstrates how you can find and navigate RUConnected. 


\section{Create a timetable to manage your time more effectively}

It is important that you plan your learning schedule carefully.

Receiving all of your lecture materials online can be overwhelming, so it is important that you manage your time effectively to stay on top of your studies.

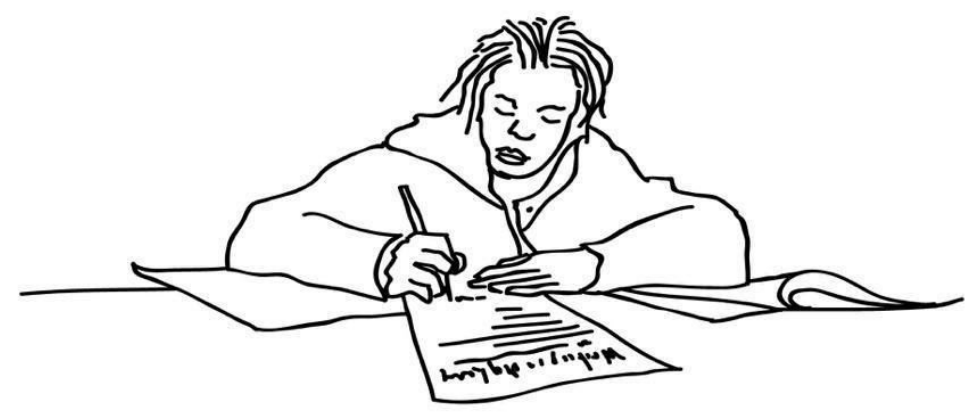

We recommend that you do daily, weekly and monthly planning to help you succeed.

(a) Daily planning

- At the start of each day, look at your weekly planner to remind yourself where you are in the curriculum and what you are working on that week. This will help you to orientate yourself.

- Check to see if any of your work from the day before has not been completed. Put this on the top of your 'to do' list. Add any new activities/tasks that need to be completed today. This will help keep you on track.

- Check your RUConnected course sites and/or email to see if you have received any announcements. This will help keep you in touch with your lecturer.

- Work in blocks of 45 minutes on specific tasks. Take 15-minute breaks in between blocks. Use this break to get up and stretch, go to the bathroom, etc. At the end of the break, return to your desk and settle down for another 45 minutes. This routine will help keep you focused on the task at hand.

- At the end of the day, tick off completed items on your 'to-do' list and make a note on your weekly calendar of any incomplete work that needs attention. This will help keep you accountable.

- Make a note of any questions you have for your lecturer or any areas of learning you struggled with. Make sure you contact your lecturer about these points or post on RUConnected communication spaces to get advice from 
your peers. It is important to stay connected during this time.

(b) Weekly planning

- At the start of each week, open up the RUConnected course site for each of your modules or courses and make a list of all the work that needs to be completed that week. This will ensure that you know what work needs to be covered.

- Break up the list of learning activities into smaller chunks and then assign a smaller activity to each day. This will make the activities more manageable and less overwhelming.

- Note down any deadlines you have for the week so that you don't get left behind (check your monthly calendar for deadlines too, so that you can schedule time to work on tasks).

- Don't forget to schedule some 'catch-up' sessions to complete unfinished work and make sure you make time to do some physical exercise - keep a healthy balance!

(c) Monthly planning

- Print, copy or draw out a monthly calendar (search for one on Google), and make a note of:

- Important deadlines relating to your learning

- Due dates of all your assignments

- Other deadlines

- Any other significant events in your life

- To keep some normality in your life, we suggest that you try and do your academic learning on weekdays and use weekend time to catch up and spend time with your family. 


\section{Find a quiet space to work}

We understand that working from home is not the ideal place for learning, given the distractions and noise. Many of you will be sharing a small space with your family members.

If possible, find a designated space to do your online learning at home. If you are able, work at a table or desk in a quiet room to minimize disturbances.

It might also be useful to have a conversation with your family members about your learning needs. Explain to them that you need a few hours a day to concentrate on your studies and make some compromises to ensure that you get this time to focus.

\section{Will I have to be connected to the internet during regular class hours?}

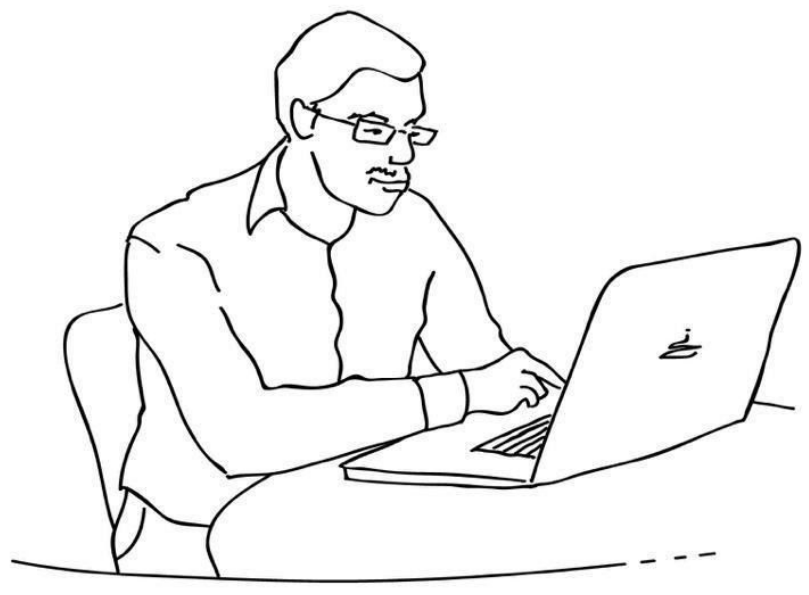

Although you will receive your learning materials online, you don't always have to be connected in order to learn.

Your lecturers will provide content on RUConnected ahead of time. This means that you can download a week's worth of content at once - you do not need to have internet connectivity every day.

\section{Keep in touch with your lecturers and peers}

Online learning can get lonely, so it is important that you keep in touch with your lecturers and your peers during this time. Although you will not be able to physically meet up, you can still interact online, via email, WhatsApp or SMS. 
Have a discussion with your lecturer and/or tutor and decide which method will work best for you and your class.

\section{What about laboratory practicals and work-integrated-learning?}

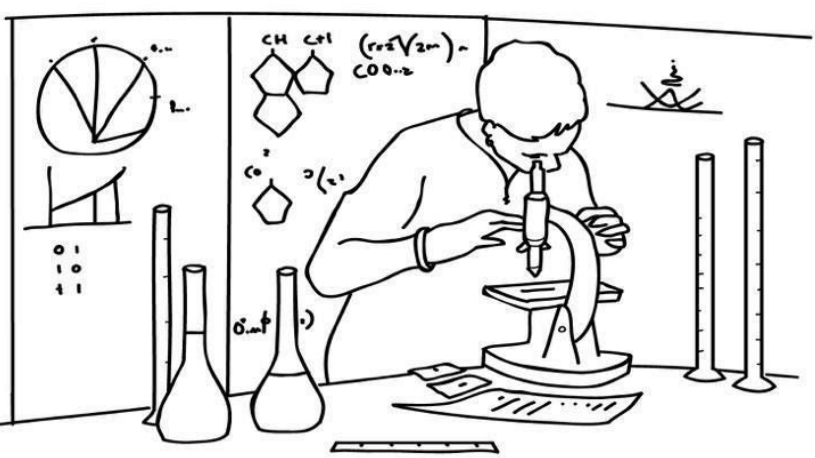

Some courses require practical experience as part of your learning experience, either in a laboratory on campus or in the field.

Your lecturers are aware of the limitations of online learning when it comes to practical learning experiences. It is likely that you will catch up on these aspects when we return to face-to-face teaching. Your lecturers will keep you up to date via RUConnected about how to proceed with this aspect.

\section{What about postgraduate supervision?}

Postgraduate supervision will also continue online as far as possible.

It is important that you get in touch with your supervisor to organize a detailed plan for supporting your postgraduate studies.

The Centre for Postgraduate Studies also has a number of activities that you can participate in via Zoom and WhatsApp to support your research. Find out more by joining their mailing list (cpgs@lists.ru.ac.za) to receive notifications about upcoming guest seminars, research workshops and synchronous writing sessions. 


\section{Keep working (and writing!)}

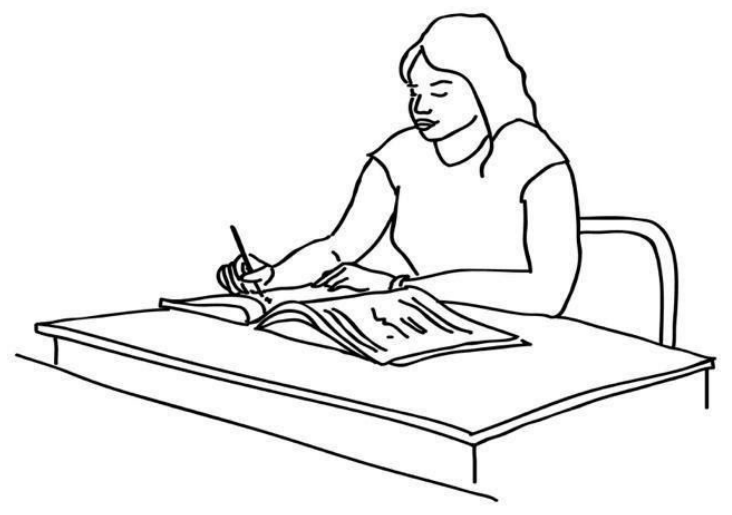

It is important that you do some work every day.

Success at online learning depends on you being diligent and disciplined about your own learning.

Developing a good routine and work schedule from the beginning will help you stay on track during this time.

And remember - even though you are receiving materials online, you must keep writing every day to clarify and develop your thinking.

\section{Ask for help}

Remember that we are navigating online learning together. This is a 'first time' experience for many of us. Your lecturers are trying their hardest to make sure that you have access to materials and that you stay on track with your learning.

Please reach out to your lecturers if you cannot access materials, if you are experiencing problems with your learning or if you feel isolated and confused. It is normal to feel some anxiety around online learning, but always remember that we are here to help you. 